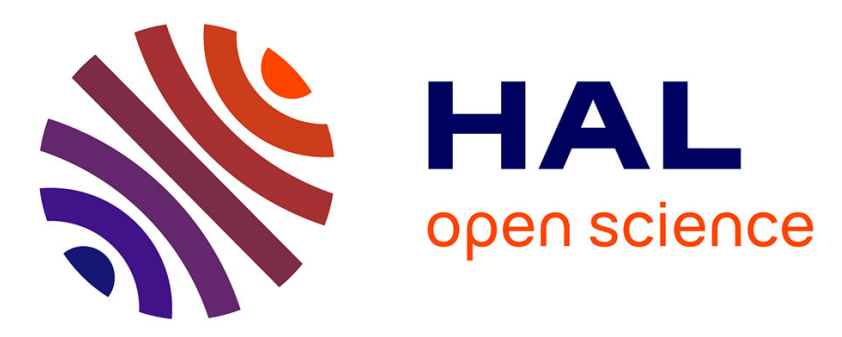

\title{
A time-resolved study of the multiphase chemistry of excited carbonyls: Imidazole-2-carboxaldehyde and halides
}

\author{
L. Tinel, S. Dumas, C. George
}

\section{- To cite this version:}

L. Tinel, S. Dumas, C. George. A time-resolved study of the multiphase chemistry of excited carbonyls: Imidazole-2-carboxaldehyde and halides. Comptes Rendus. Chimie, 2014, 17 (7-8), pp.801807. 10.1016/j.crci.2014.03.008 . hal-01116221

\author{
HAL Id: hal-01116221 \\ https://hal.science/hal-01116221
}

Submitted on 13 Feb 2015

HAL is a multi-disciplinary open access archive for the deposit and dissemination of scientific research documents, whether they are published or not. The documents may come from teaching and research institutions in France or abroad, or from public or private research centers.
L'archive ouverte pluridisciplinaire HAL, est destinée au dépôt et à la diffusion de documents scientifiques de niveau recherche, publiés ou non, émanant des établissements d'enseignement et de recherche français ou étrangers, des laboratoires publics ou privés. 


\title{
A time resolved study of the multiphase chemistry of excited carbonyls: imidazole-2- carboxaldehyde and halides
}

\author{
Liselotte Tinel, Stéphane Dumas, Christian George*
}

Université de Lyon, F-69626, France; Université de Lyon 1, Lyon, F-69626, France; CNRS, UMR5256, IRCELYON, Institut de Recherche sur la Catalyse et l'Environnement de Lyon, F-

\author{
69626, France \\ liselotte.tinel@ircelyon.univ-lyon1.fr \\ stephane.dumas@univ-lyon1.fr \\ *christian.george@ircelyon.univ-lyon1.fr
}

\begin{abstract}
:
Imidazole-2-carboxaldehyde (IC) reactivity in presence of halide anions $\left(\mathrm{Cl}^{-}, \mathrm{Br}^{-}, \mathrm{I}^{-}\right)$has been studied by laser flash photolysis in aqueous solution at room temperature. The absorption spectrum of the triplet state of IC has been measured with maximum absorption at $330 \mathrm{~nm}$ and a weaker absorption band around $650 \mathrm{~nm}$. Iodide anions showed to be efficient quenchers of triplet state IC, with rate coefficient $k_{q}$ determined at $(5.33 \pm 0.25) \times 10^{9} \mathrm{M}^{-1} \mathrm{~s}^{-1}$. The quenching by bromide and chloride anions was less efficient, $k_{q}$ respectively $(6.27 \pm 0.53) \mathrm{x}$ $10^{6} \mathrm{M}^{-1} \mathrm{~s}^{-1}$ and $(1.31 \pm 0.16) \times 10^{5} \mathrm{M}^{-1} \mathrm{~s}^{-1}$. The halide $\left(\mathrm{X}^{-}\right)$quenches the triplet state; the resulting transient absorption feature matches that of the corresponding radical anion $\left(\mathrm{X}_{2}^{-}\right)$. We suggest that this type of quenching reactions is a driving force of oxidation reactions in the oceanic surface micro-layer (SML) and a source of halogen atoms in the atmosphere.
\end{abstract} Key words: laser flash photolysis, imidazole-2-carboxaldehyde, iodide, bromide, chloride, surface micro-layer, marine boundary layer 


\section{Introduction}

A significant fraction of the carbon atoms present in dissolved natural organic material bear carbonyl groups [1]. These carbonyls, and more particularly aromatic carbonyls, are thought to be important photooxidants for various phenols present in natural waters. Aromatic ketones absorb in the natural emission spectrum of the sun and their photoactivated states react with phenols at rates close to the diffusion-controlled limit [2]. Canonica and co-workers brought into evidence that this photooxidation involved proton or electron transfer from the triplet excited state of the carbonyl functionalities, which showed to be important oxidants despite their rather short lifetime [3,4]. Aromatic ketones, like benzophenone, also oxidize efficiently sea salt halides after absorption of actinic sunlight [5]. Photosensitized reactions of aromatic carbonyls are not only known oxidants in natural waters, but showed also to be an important source of hydrogen peroxide in atmospheric aerosols [6].

Imidazole-2-carboxaldehyde (IC), bearing a carbonyl function, and other imidazoles get growing interest in atmospheric chemistry, since their presence in secondary organic aerosols (SOA) has been explained by a catalytic process in situ involving ammonium salts and glyoxal, an ubiquitous organic compound in the troposphere $[7,8]$. This catalytic product formation in aerosols explains part of the missing glyoxal in the gas-phase through an uptake of glyoxal that was ignored for a long time $[9,10]$. Recently, it has been shown that imidazole2-carboxaldehyde, one of the products formed by the 'iminium-pathway', can efficiently photo-induce the growth of aerosols [11]. This compound is thus a secondary formed photosensitizer and can play an important role in SOA growth in the absence of gas-phase oxidants under light conditions. The presence of these nitrogen containing compounds in particles can also lead to changes in the optical properties of the aerosol, hence affecting the aerosols' radiative forcing and cloud properties $[12,13]$. 
Imidazole compounds are also known to be present in the sea and at the sea surface microlayer (SML) $[14,15]$. Glyoxal has been measured in the marine boundary layer (MBL) [16] and amines are an important constituent of marine aerosols [17], which comforts the hypothesis of formation of imidazoles in the marine environment. The SML shows also an enrichment of nitrogen content during periods of high biological activity [18]. The organicenriched SML, the thin interfacial zone between the atmosphere and the subsurface water, presents different chemical and physical features than the underlying water and plays an important role in the sea-air chemical interactions. Ozone loss from the marine boundary layer (MBL), for example, can occur through the reactive uptake of ozone by plant exudates such as chlorophyll present in the SML [19,20,21]. SML samples also feature higher absorption in UV-region than the bulk, implying that photochemical processes can be important in transformations in and between dissolved and particulate matter [18].

Photoactive compounds, found in a higher concentration in the SML than in the underlying water, can also produce active halogen species after oxidation of the halides present in the MBL, both as aerosols and in the sea water. Photo-activated aromatic carbonyls, like benzophenone, and other photoactive compounds like chlorophyll, can lead to the formation of the reactive radical anion $\left(\mathrm{X}_{2}{ }^{\bullet-}\right)$ and molecular halogens, that can be released in the gas-phase $[5,22]$. This kind of direct photochemical reactions at the interface could account for a part of the halides observed over open oceans [23]. Gas-phase halogen atoms, especially iodine and bromine, will set in catalytic cycles of ozone destruction in the MBL, thus changing locally the oxidizing capacities. Gas-phase iodine chemistry can also give rise to particle formation [24,25], while chlorine will be incline to oxidize hydrocarbons [26].

Other sources of such reactive halogen atoms in the MBL include photolysis of polyhalogenated compounds emitted by algae [27], heterogeneous chemistry of ozone or $\mathrm{NO}_{\mathrm{y}}$ on snow or sea-salt particles [28] and particularly for chlorine, photochemical reactions at the 
air-sea interface [29]. Halogen chemistry is thus profoundly entwined with the aerosol production and oxidizing strength of the MBL, affecting potentially the cloud condensation nuclei and hence climate change.

The aim of this work is to explore the photochemical properties of imidazole-2carboxaldehyde (IC), a secondary photosensitizer potentially present in the marine environment and known to induce particle growth as a secondary formed photosensitizer and to examine the bimolecular rate coefficients of this compound in presence of halide anions, $\mathrm{Cl}^{-}, \mathrm{Br}^{-}$and $\mathrm{I}^{-}$by means of laser flash photolysis.

\section{Experimental}

Laser flash photolysis: The transient absorption spectrum of the excited IC was followed with a classical laser flash photolysis apparatus [20]. The photolysis excitation source was the third harmonic (266 nm, pulse width 7 ns) of a Nd:YAG laser (Surelite II 10, Continuum) operated in the single-shot mode. The choice of the wavelength is justified by the maximum of absorption of IC at $290 \mathrm{~nm}$, as can be seen from the absorption spectrum shown on figure 1, even if it has been shown that at wavelengths $>290 \mathrm{~nm}$, IC can induce a photosensitized reaction [11].

During the experiments, the laser pulse energy was limited at $15 \mathrm{~mJ}$ per pulse $(\sim 39$ $\mathrm{mJ} / \mathrm{cm}^{2}$ ) to limit as much as possible photolysis of the photosensitizer and therefore the possible interferences of its products on the studied chemistry, but also two photons excitation. The laser output passed through the aperture in the short axis (4 mm path length) of a fully masked quartz flow cell, mounted at $13 \mathrm{~cm}$ of the laser output. The solution containing the photosensitizer was introduced in the flow cell of $450 \mu \mathrm{L}$ by means of a peristaltic pump, with a flow of $1.6 \mathrm{~mL} / \mathrm{min}$, ensuring a complete purge of the exposed 
volume every 17 seconds. This limited the exposition of the introduced solution to 3-4 laser shots and maintained a constant temperature in the flow cell. All connections where made from either glass or PTFE tubing, ensuring a clean liquid flow.

Transient species produced by the pulsed laser beam were monitored by means of time-resolved absorption spectroscopy. The analyzing light, provided by a $75 \mathrm{~W}$ highpressure Xenon arc lamp (LOT-Oriel), passed through the two apertures of long axis of the flow cell (1 cm path length). The light was then collected by a $1 / 4 \mathrm{~m}$ monochromator (Spectral Products DK240) equipped with a 2400 grooves/mm grating and detected by a photomultiplier (Hamamatsu H7732-01). The PMT signal was passed through a high-speed current amplifier/discriminator (Femto) and the AC component recorded on a $300 \mathrm{MHz}$ oscilloscope (Tektronix TDS3032c). The digitalized signal was then transferred to a computer for further processing. Typically, 16 measurements were averaged at each wavelength to obtain a transient absorption spectrum, with an accuracy of $3 \%$. The full transient absorption spectrum was then reconstructed from the steady and transient signals. For construction of an absorption spectrum, measurements were repeated every 10-20 nm between $320 \mathrm{~nm}$ and 720 $\mathrm{nm}$, limits determined by the measuring system; for the kinetics, the probe wavelengths for the transient absorption decay of triplet state of IC were $330 \mathrm{~nm}$ and $350 \mathrm{~nm}$.

For the analysis of triplet state decays of IC in pure water, linear regression on a logarithmic plot of the data and a mono-exponential decay model fits were performed on the same data sets. As the results of both fitting methods were comparable, we will here only present the results obtained by non-linear fits.

Materials and solutions: All the experiments were performed at room temperature in the range 295-300 K. Aqueous solutions containing 0.25mM of IC were deoxygenated with nitrogen for 20 minutes prior to analysis and kept under a continuous stream of nitrogen during the experiment. All solutions were freshly prepared using $18 \mathrm{M} \Omega$ ultra pure water 
(ELGA) and were put in an ultrasonic bath for $10 \mathrm{~min}$. to promote solubility. The chemicals used in this study - imidazole-2-carboxaldehyde (Aldrich, 97\%), sodium chloride (>99\% Sigma-Aldrich), sodium iodide (>99\% Sigma-Aldrich), sodium bromide (>99\% SigmaAldrich) - were all used without further purification. The known impurity of bi-imidazole in the commercial imidazole-2-carboxaldehyde did not notably interfere, since no absorption for triplet state bi-imidazole was detected. In our conditions, aqueous solutions of $\mathrm{pH} 6.5$, IC is expected to be in its aldehyde form [30].

\section{Results}

\subsection{Characteristics of the triplet state imidazole-2-carboxaldehyde}

Laser flash photolysis of $\mathrm{N}_{2}$-saturated solutions of $0.25 \mathrm{mM}$ IC in pure water showed strong transient absorptions, as shown in figure 1. The transient absorption of excited IC also shows intense fluorescence in the first nanoseconds after the laser pulse. Figure 2 shows recorded transient absorption spectra at different time intervals after the laser pulse, demonstrating the

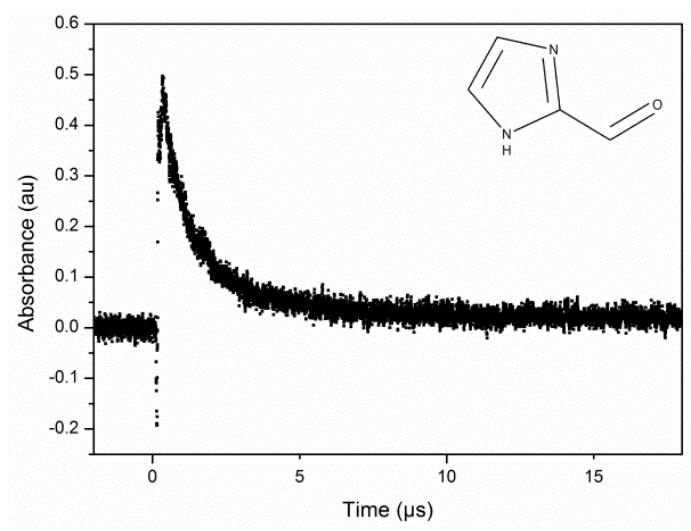

Figure 1: Transient absorption decay obtained at $330 \mathrm{~nm}$ of the IC triplet state in a deoxygenated aqueous solution of $0.25 \mathrm{mM} \mathrm{IC}$ 


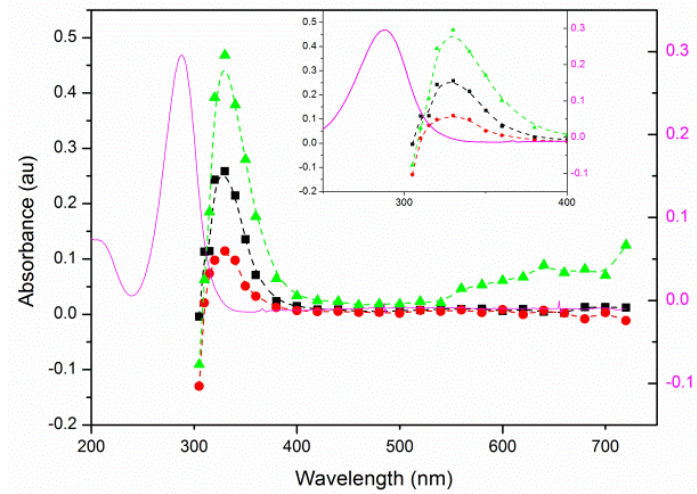

Figure 2: Absorption spectrum of aqueous solution of IC (0.25 mM) recorded $330 \mathrm{~ns}(\mathbf{\square}), 1 \mu \mathrm{s}$ $(\bullet)$ and $2 \mu \mathrm{s}(\Delta)$ after the laser pulse. The solid line $(-)$ shows the absorption spectrum of a solution of $0.25 \mathrm{mM} \mathrm{IC}$ (right Y scale). The insert is a zoom of the spectrum from $250 \mathrm{~nm}$ to $400 \mathrm{~nm}$.

uniform decrease of the absorbance without formation of any significant band. The absorption spectrum can thus be attributed to the triplet-triplet absorption of ${ }^{3} \mathrm{IC}^{*}$ and was recorded for the first time, since very little is known about the photochemistry of IC. The transient absorption spectrum recorded after the laser pulse is characterized by a strong absorption peak with a maximum absorption wavelength around $330 \mathrm{~nm}$ and a weaker broad absorption band around $650 \mathrm{~nm}$. For the determination of lifetimes and quenching rate coefficients, the decay of the triplet state was monitored at $330 \mathrm{~nm}$.

The absorption decay trace of excited ${ }^{3} \mathrm{IC}^{*}$ at $330 \mathrm{~nm}$ fitted well a single exponential process of the form:

$$
y=a+b e^{-t k_{1}}
$$

over the $0-10 \mu$ s region with $\mathrm{k}_{1}=(8.87 \pm 0.11) \times 10^{5} \mathrm{~s}^{-1}$. The lifetime of the triplet state of $\mathrm{IC}$, defined as

$$
\tau=\frac{1}{k_{1}}
$$

could thus be determined and was found to be $\tau=1.21 \mu \mathrm{s}$ in a deoxygenated solution. This lifetime seems to be in accordance with a triplet state excitation, for which lifetimes are expected to be in the range of $10^{-7}$ to $1 \mathrm{~s}$ [31]. Other photosensitizers like pterin have a reported triplet state lifetime of the same order $(2.3 \pm 0.2 \mu \mathrm{s})[32]$. 
In presence of oxygen, the lifetime of the triplet state decreased in an oxygen saturated solution, which indicates that an energy transfer to oxygen is possible. In an air saturated solution the quenching constant for the reaction with oxygen was estimated at $3.9 \times 10^{9} \mathrm{M}^{-1} \mathrm{~s}^{-1}$, assuming that the concentration of oxygen is described by Henry's law. This fast energy transfer could generate reactive oxygen species such as singlet oxygen or superoxide anions.

\subsection{Quenching}

The reaction of ${ }^{3} \mathrm{IC}^{*}$ with 3 sea salt halides i.e. chloride, bromide and iodide was investigated. These salts are present in different and varying concentrations in the seawater (and aerosols); the average chloride concentration is around $0.54 \mathrm{M}$, bromide concentrations around $0.84 \mathrm{mM}$ and iodide varying between $0.02 \mu \mathrm{M}$ and $0.4 \mu \mathrm{M}[33,34]$. Previous studies have shown that sea salts, like phenols, can act as electron donors towards the excited carbonyls forming reactive halide radicals $[4,5]$. The reaction mechanism for the growth of aerosols containing traces of IC, proposed in Aregahegn et al. [11], suggests that the excited state ${ }^{3} \mathrm{IC}^{*}$ can act through a proton or an electron transfer from limonene towards IC. In this study, photoactivated IC is expected to interact with the halide anions by electron transfer to produce atomic halogens [5]:

$$
{ }^{3} \mathrm{IC}^{*}+\mathrm{X}^{-} \rightarrow \mathrm{IC}^{\bullet-}+\mathrm{X}^{\bullet}
$$

The reactivity of the three quenchers was investigated by introducing $\mathrm{NaI}, \mathrm{NaBr}$ or $\mathrm{NaCl}$ in different concentrations in deoxygenated aqueous solutions of IC, with a large excess of the quencher towards the photosensitizer, respecting pseudo-first order conditions. The quenching rates coefficients for ${ }^{3} \mathrm{IC} *$ in presence of the halides were determined by the Stern-Volmer equation (eq. 3):

$$
-\frac{d\left[{ }^{3} I C^{*}\right]}{d t}=\left(k_{0}+k_{q}\left[X^{-}\right]\right)\left[{ }^{3} I C^{*}\right]=k_{o b s}\left[{ }^{3} I C^{*}\right]
$$


where $k_{0}$ is the rate coefficient of the triplet state decay in the absence of oxygen and $k_{q}$ the rate coefficient for the quenching process by the halide $X^{-}[31]$. A Stern-Volmer plot of the observed rate coefficient $k_{o b s}$ in function of the concentration of the quencher $\mathrm{X}^{-}$permits to obtain the quenching rate coefficient $k_{q}$ from the slope of the curve.

\subsubsection{Iodide}

The decay of the triplet-triplet absorption monitored at $330 \mathrm{~nm}$ in the presence of NaI showed still a mono-exponential decay, but decreased much faster in presence of increasing concentration of $\mathrm{I}^{-}$(fig. 3).

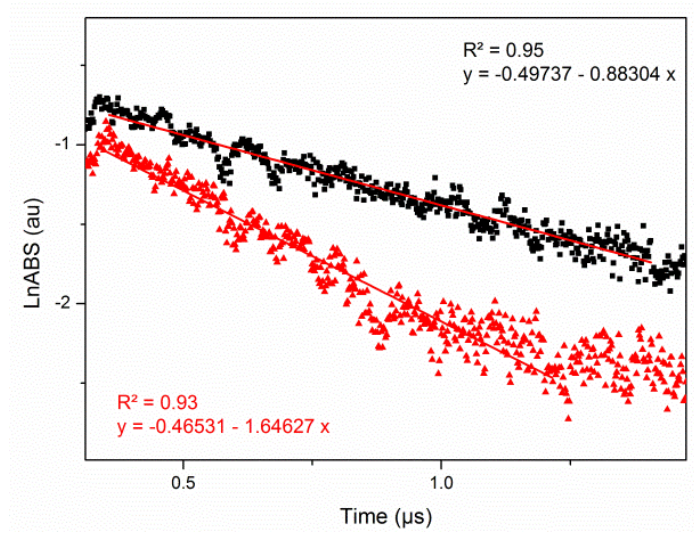

Figure 3: Log plot of a transient absorption decay obtained at $330 \mathrm{~nm}$ of the IC triplet state in a deoxygenated aqueous solution of $0.25 \mathrm{mM} \mathrm{IC}$ alone (-) and in presence of $0.25 \mathrm{mM} \mathrm{NaI}$ ( $\mathbf{\Delta})$ and the linear fits showing a greater slope in presence of NaI

The quenching rate coefficient $k_{q}\left(\mathrm{I}^{-}\right)$obtained for ${ }^{3} \mathrm{IC}^{*}$ by $\mathrm{I}^{-}$from the slope of the SternVolmer plot shown figure 4 , is $k_{q}\left(\mathrm{I}^{-}\right)=(5.33 \pm 0.25) \times 10^{9} \mathrm{M}^{-1} \mathrm{~s}^{-1}$. The high rate coefficient obtained is close to the diffusion controlled limit and shows that the quenching by the iodide anion is highly efficient.

\subsubsection{Bromide}

Triplet-triplet absorption decay of IC was also faster in presence of increasing concentrations of $\mathrm{NaBr}$, remaining mono-exponential at $330 \mathrm{~nm}$ for concentrations of bromide $<200 \mathrm{mM}$. From the Stern-Volmer plot (fig. 4), the quenching rate coefficient determined was $k_{q}\left(\mathrm{Br}^{-}\right)=$ $(6.27 \pm 0.53) \times 10^{6} \mathrm{M}^{-1} \mathrm{~s}^{-1}$ for bromide. The quenching rate coefficient is orders of magnitude 
lower than the quenching rate for iodide and also quite slow compared to the rates obtained with other photosensitizers, such as benzophenone, where values for quenching rates for bromide are comprised between $2.2-3.5 \times 10^{8} \mathrm{M}^{-1} \mathrm{~s}^{-1}[5,33]$.

\subsubsection{Chloride}

In the presence of chloride, the absorbance of ${ }^{3} \mathrm{IC}^{*}$ showed only small decreased lifetimes, even with chloride concentrations up to $1 \mathrm{M}$ (fig. 4). The quenching rate coefficient determined is $k_{q}\left(\mathrm{Cl}^{-}\right)=(1.31 \pm 0.16) \times 10^{5} \mathrm{M}^{-1} \mathrm{~s}^{-1}$ and in view of the coefficients obtained for the other halides, we can conclude that the quenching of triplet state IC by chloride is not efficient.

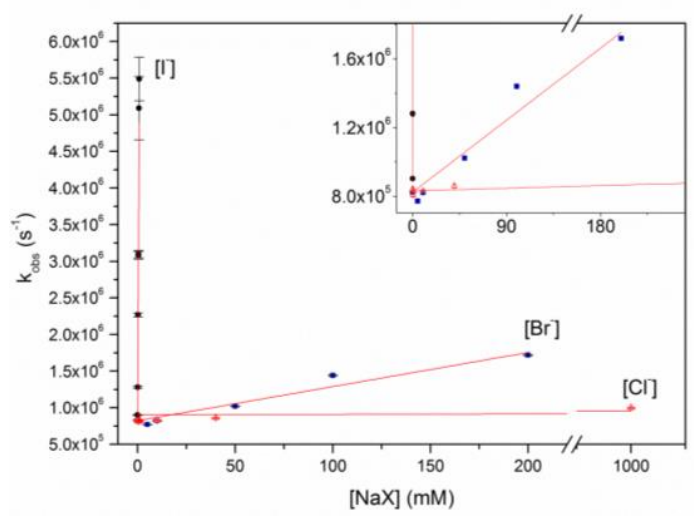

Figure 4: Stern-Volmer plot of the pseudo-first order rate coefficients $k_{\text {obs }}$ of IC triplet state quenching in function of the halide concentrations.

\subsubsection{Comparison of the three quenchers}

When considering the three quenching rate coefficients, it comes into evidence that the quenching rate coefficients are linked to the oxidation potentials of the used halides. Table 1 lists the quenching rate coefficients and the oxidation potentials for each halide. For the halide with the lowest oxidation potential, iodide, the quenching rate coefficient obtained is four orders of magnitude higher than the quenching rate coefficient obtained for chloride. It seems thus probable that the excited triplet state of IC is quenched by these halides by an electron 
transfer towards ${ }^{3} \mathrm{IC}^{*}$. Electron transfer from a halide $\left(\mathrm{X}^{-}\right)$to the excited triplet state of a carbonyl compound yields a halide radical and a ketyl radical.

Table I: The oxidation potential $E\left(X^{-} / X\right)$ of each halide and their quenching rate coefficients $K_{q}$ obtained for ${ }^{3} I^{*}$

\begin{tabular}{ccc}
\hline Quencher & $\begin{array}{c}\mathbf{E}\left(\mathbf{X} / \mathbf{X}^{-}\right)(\mathbf{V}) \\
{[36]}\end{array}$ & $\mathbf{k}_{\mathbf{q}}\left(\mathbf{M}^{-\mathbf{1}} \mathbf{s}^{\mathbf{- 1}}\right)$ \\
\hline $\mathrm{Cl}^{-}$ & 2.6 & $(1.31 \pm 0.19) \times 10^{5}$ \\
$\mathrm{Br}^{-}$ & 1.93 & $(6.27 \pm 0.53) \times 10^{6}$ \\
$\mathrm{I}^{-}$ & 1.33 & $(5.33 \pm 0.25) \times 10^{9}$ \\
\hline
\end{tabular}

Such an intramolecular electron transfer is usually described by a mechanism, schematized in equation 2, involving the formation of a contact complex, after which the electron transfer takes place and a charge complex is formed. Finally, the charge complex breaks up and oxidized donor and reduced acceptor are separated.

$$
{ }^{3}(\mathrm{IC})^{*}+\mathrm{X}^{-} \rightleftarrows\left[{ }^{3}(\mathrm{IC})^{*} \ldots \mathrm{X}^{-}\right] \rightleftarrows\left[\mathrm{IC}^{\bullet-} \ldots \mathrm{X}^{\bullet}\right] \rightarrow \mathrm{IC}^{\bullet-}+\mathrm{X}^{\bullet}
$$

This mechanism requires the free enthalpy of the electron transfer $\left(\Delta \mathrm{G}_{\mathrm{ET}}\right)$ to be negative or close to zero for the electron transfer to become thermodynamically favorable $[5,35]$. It could be interesting to compare the free enthalpy of the electron transfer for each quencher, if the reduction potential of IC and the energy of the triplet state of the photosensitizer were known. It seems that iodide, the halide with the lowest electronegativity, will be the best electron donor and consequently the most efficient quencher, hence the highest rate coefficient determined. Chloride on the other hand displays the highest electronegativity and oxidation potential and is a poor electron donor. The rate coefficient of the quenching with chloride was, as expected, lower than for bromide and iodide. The energy of triplet state IC is thus expected to be higher than the oxidation energy of iodide and lower than the oxidation energy of bromide, since the rate for the electron transfer from iodide is close to the diffusion 
limited rate but substantially lower for bromide. The electron transfer from chloride is thermodynamically unfavorable as is reflected by the very low rate coefficient.

\subsection{Discussion}

In the mechanism (E.2) proposed above, there is formation of halogen atom radicals. These radicals are very reactive, can form secondary products and give rise to transient product absorption. By establishing transient absorption spectra at different times after the laser pulse and for different concentrations of halogens, transient absorption products could be detected in presence of iodide and bromide. No radical product formation was observed following the excitation of IC in presence of chloride, since the quenching reaction with chloride was shown to be much slower.

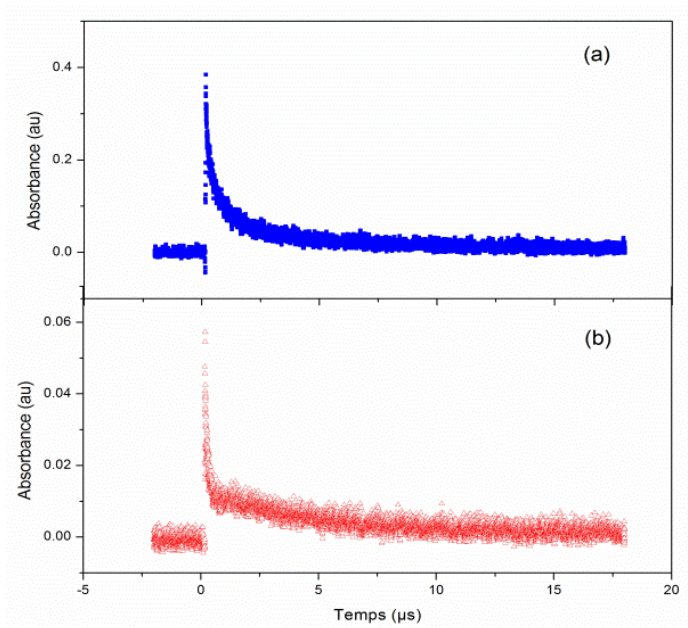

Figure 5: Transient absorption decay of ${ }^{3} \mathrm{IC}^{*}($ a) in presence of $300 \mathrm{mM} \mathrm{NaBr}(\mathbf{\square})$ monitored at $355 \mathrm{~nm}$ and (b) in presence of $0.4 \mathrm{mM} \mathrm{NaI}(\Delta)$ monitored at $380 \mathrm{~nm}$, showing a biexponential decay.

\subsubsection{Iodide}

As mentioned in the previous section, the decays of absorption of ${ }^{3} \mathrm{IC} *$ in presence of iodide could be fitted by a mono-exponential function at wavelengths around $330 \mathrm{~nm}$, the maximum absorption of ${ }^{3} \mathrm{IC}^{*}$. At longer wavelengths, particularly at $380 \mathrm{~nm}$, as illustrated by figure 5 , the decays fitted a bi-exponential decay of the form: 


$$
y=a+b_{1} e^{-t k_{1}}+b_{2} e^{-t k_{2}}
$$

providing evidence for the existence of a species with a short lifetime and a species with a longer lifetime absorbing at this wavelength. The short lifetime could be attributed to the absorption of ${ }^{3} \mathrm{IC}^{*}$, since the lifetime of this species increased with decreasing NaI concentration, leading to a decay similar to the decay of ${ }^{3} \mathrm{IC}^{*}$ in pure water at that wavelength, and tending to be mono-exponential at low NaI concentrations $(0.1 \mathrm{mM})$.

After comparison of absorption spectra at different times after the laser pulse, the absorption at $380 \mathrm{~nm}$ of the species with the longer lifetime could be observed several $\mu$ s after the laser pulse and was stronger, though still low, than the absorption of a solution of IC in pure water (fig. 6). The comparison of the absorption spectrum of ${ }^{3} \mathrm{IC}^{*}$ in pure water with the absorption spectrum of ${ }^{3} \mathrm{IC}^{*}$ in presence of $0.4 \mathrm{mM}$ of NaI after shorter time intervals after the laser pulse, illustrated by the insert of figure 6 , does not feature this enhanced absorption around $380 \mathrm{~nm}$. This indicates clearly a secondary formation for the species absorbing at 380 nm.

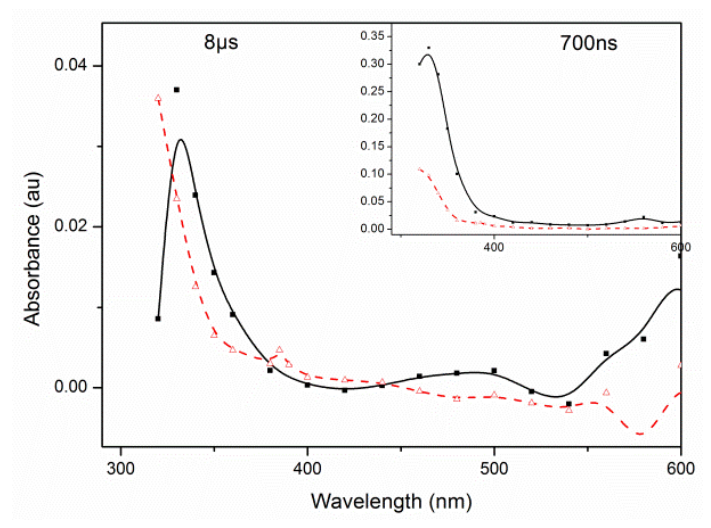

Figure 6: Absorption spectrum of IC $(0.25 \mathrm{mM})$ in presence of $\mathrm{NaI}(0.4 \mathrm{mM})$ registered at $8 \mu \mathrm{s}$ after the laser pulse, showed as --- $\Delta$, featuring a peak around $385 \mathrm{~nm}$, not observed in the absorption spectrum of IC alone (-). At shorter times after the laser pulse (700 ns, insert), the spectrum of IC in presence of $\mathrm{NaI}(---\Delta)$ is less intense at all wavelengths than the spectrum of IC only (-).

One of the products that are possibly formed by the atom radical $\mathrm{I}^{\bullet}$ is the radical anion $\mathrm{I}_{2}{ }^{\bullet-}$, formed by the combination of the anion with the oxidized halide radical. This well known 
transient species shows absorption maxima at $385 \mathrm{~nm}$ and at $725 \mathrm{~nm}$ is relatively stable, hence showing a long lifetime $[37,38,39]$. Our system did not permit to detect the second absorption peak of $\mathrm{I}_{2}{ }^{\bullet-}$ at $725 \mathrm{~nm}$, which intensity is expected to be 3.5 times lower than the intensity of the peak around $385 \mathrm{~nm}$. The peak of $\mathrm{I}_{2}{ }^{\circ-}$ is low, despite the rather high molar absorption of this transient species $\left(9600 \mathrm{~cm}^{-1} \mathrm{~mol}^{-1}\right)$ [38]. This could be explained by rapid $\mathrm{I}_{2}$ formation [40] or by fast scavenging reactions of $\mathrm{I}^{*}$ and $\mathrm{I}_{2}{ }^{\circ-}$, limiting the amount of $\mathrm{I}_{2}{ }^{-}$ detected, as has been showed in the case of chloride [41]. These radical reactions are possible with the solvent or with the photosensitizer [42,5], which could explain the high absorption, even $8 \mu \mathrm{s}$ after the laser pulse at wavelengths $<330 \mathrm{~nm}$ (fig. 6). The radical $\mathrm{I}_{2}{ }^{-}$is the only species expected to absorb at $380 \mathrm{~nm}$ and the peak can thus distinctively be attributed to this transient species. The absorption at shorter wavelengths cannot be completely monitored with our system and would not be characteristic for one expected transient species.

\subsubsection{Bromide}

The transient species formed after the photooxidation of bromide by ${ }^{3} \mathrm{IC}^{*}$ were more difficult to follow, since the absorbance of one the expected products, $\mathrm{Br}_{2}{ }^{-}$, was overlapping with the absorbance of triplet state IC. Nonetheless, the fitted curves at the maximum absorption, 330 $\mathrm{nm}$, of the triplet state IC, showed a mono-exponential decay in presence of bromide concentrations in the range of $1-200 \mathrm{mM}$. The decay became bi-exponential for wavelengths around $354 \mathrm{~nm}$, the maximum absorption of $\mathrm{Br}_{2}{ }^{-}$in water [43], indicating secondary product formation. As in the case of iodide, two species with distinct lifetimes could be distinguished, the short lived ascribed to the decay of ${ }^{3} \mathrm{IC}^{*}$. On the absorption spectrum (figure 7) taken 10 $\mu \mathrm{s}$ after the laser pulse, the absorption around $360 \mathrm{~nm}$ is higher in presence of bromide than the absorption obtained with IC alone. This could be due to the formation of $\mathrm{Br}_{2}^{-{ }^{-}}$, a strong 
absorbing radical species $\left(\varepsilon_{\max }=9900 \mathrm{M}^{-1} \mathrm{~cm}^{-1}[40]\right)$ formed from the reaction of $\mathrm{Br}^{\bullet}$ with $\mathrm{Br}^{-}$

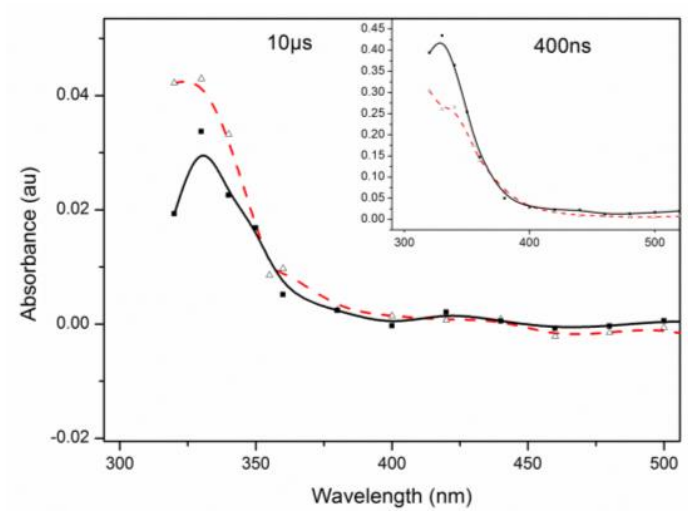

Figure 7: Absorption spectrum of IC $(0.25 \mathrm{mM})$ in presence of $\mathrm{NaBr}(300 \mathrm{mM})$ showing higher absorption around $360 \mathrm{~nm}(---\Delta)$ than the absorption spectrum of IC alone (-), registered at $10 \mu \mathrm{s}$ after the laser impuls. At shorter times after the laser impuls (400 $\mathrm{ns,}$ insert), the spectrum of IC in presence of $\mathrm{NaBr}(---\Delta)$ is less intense at all wavelengths than the spectrum of IC only (-).

Figure 7 also shows increased absorption for wavelengths shorter than $355 \mathrm{~nm}$, even at long times after the laser pulse, absorption not explained by the triplet state IC absorption. This absorption, detected only partially with our apparatus, shows a large peak with a rather long lifetime. Products contributing to this absorption could be recombination products of IC with $\mathrm{Br}^{\circ}$ or the very strong absorbing $\mathrm{Br}_{3}^{-}\left(\varepsilon_{\max }=40900 \mathrm{M}-1 \mathrm{~cm}-1, \lambda_{\max }=266 \mathrm{~nm} \mathrm{[44]).}\right.$

The absorption of $\mathrm{Br}_{2}{ }^{-}$seems rather low, indicating that $\mathrm{Br}_{2}{ }^{--}$is not a major product of this photooxidative process. This could be due to $\mathrm{Br}_{2}$ formation or scavenging reactions of $\mathrm{Br}^{\circ}$ and $\mathrm{Br}_{2}{ }^{--}$by the solvent or the photosensitizer [45]. One of the products possibly formed from the reaction of $\mathrm{Br}^{*}$ with water is $\mathrm{BrOH}^{*}$ [45]. This radical shows a maximum absorption at 352 $\mathrm{nm}$, very similar, but less intense, to the absorption $\mathrm{Br}_{2}{ }^{-}[43]$, but the reaction of $\mathrm{Br}^{\bullet}$ with water is very slow $\left(\mathrm{k}=1.4 \mathrm{~s}^{-1}\right.$, in [45]). Even if the absorption at this wavelength cannot be unambiguously ascribed to $\mathrm{Br}_{2}{ }^{-}$the formation of $\mathrm{BrOH}^{-}$can thus be considered negligeable.

\subsubsection{Proposed mechanism:}


To resume the reactions and the formation of the products detected, the proposed mechanism involves the following reactions:

$$
\begin{aligned}
& \mathrm{IC}^{*}+\mathrm{X}^{-} \rightarrow \mathrm{IC}^{\bullet-}+\mathrm{X}^{\bullet} \\
& \mathrm{X}^{\bullet}+\mathrm{IC} \rightarrow \text { products } \\
& \mathrm{X}^{\bullet}+\mathrm{X}^{-} \rightleftarrows \mathrm{X}_{2}^{\bullet-} \\
& \mathrm{X}_{2}{ }^{--}+\mathrm{IC} \rightarrow \text { products } \\
& \mathrm{X}_{2}{ }^{\bullet-}+\mathrm{X}_{2}{ }^{\bullet-} \rightleftarrows \mathrm{X}_{3}^{-}+\mathrm{X}^{-} \\
& \mathrm{X}_{3}{ }^{-} \rightleftarrows \mathrm{X}_{2}+\mathrm{X}^{-} \\
& \mathrm{X}^{\bullet}+\mathrm{X}^{\bullet} \rightarrow \mathrm{X}_{2} \\
& \mathrm{X}_{2}{ }^{\cdot-}+\mathrm{X}_{2}{ }^{\bullet-} \rightarrow \mathrm{X}_{2}+2 \mathrm{X}^{-} \\
& \mathrm{X}_{2} \rightleftarrows \mathrm{X}_{2}(\mathrm{~g})
\end{aligned}
$$

This mechanism explains the formation of reactive radicals and can lead to the formation of halogen molecules in the gas phase.

\section{Summary and atmospheric implications}

Our results confirm the role of IC as photosensitizer proposed by Aregahegn et al. [11], for the first time evidencing the existence of a triplet state for this compound. The lifetime of ${ }^{3} \mathrm{IC} *$ is estimated at $1.21 \mu \mathrm{s}$ in a deoxygenated aqueous solution and the maximum absorbance was measured at $330 \mathrm{~nm}$.

The triplet state of IC was efficiently quenched by iodide, $k_{q}\left(\mathrm{I}^{-}\right)=(5.33 \pm 0.25) \times 10^{9}$ $\mathrm{M}^{-1} \mathrm{~s}^{-1}$, and much less by bromide, $k_{q}\left(\mathrm{Br}^{-}\right)=(6.27 \pm 0.53) \times 10^{6} \mathrm{M}^{-1} \mathrm{~s}^{-1}$. Chloride showed a slow quenching rate, $k q\left(\mathrm{Cl}^{-}\right)=(1.31 \pm 0.16) \times 10^{5} \mathrm{M}^{-1} \mathrm{~s}^{-1}$ and reactions with chloride might thus be negligible. Reactions with these halides form atomic halogens, some of which could be detected by increased transient absorption. Also, the quenching rate constants show the 
same trends as the oxidation potential of each sea salt anion, suggesting an electron transfer is the mechanism behind the photooxidation of the halides.

Imidazole-2-carboxaldehyde showed to be a quite efficient photosensitizer and, as IC can also be formed in aerosols in presence of glyoxal and ammonia, its presence, even in traces, could have an important influence on the particle phase chemistry at the interface of aerosols. Its photosensitized reactions can lead to an uptake of gas-phase VOCs and lead to particle growth, as demonstrated by the works in [11]. The photochemical radical production mechanism initiated by carbonyl compounds proposed in this study is potentially important in the SML, not only in reactions with sea salts but also for the oxidation of other organic compounds with a one electron oxidation potential. Indirectly, photochemistry evidenced for IC and other carbonyl compounds may also influence the chemistry of the SML by the radicals and secondary products formed during this process and the MBL by the release of reactive (halogenated) species, such as $\mathrm{Br}_{2}, \mathrm{Br}_{2}{ }^{\bullet-}, \mathrm{I}_{2}$ and $\mathrm{I}_{2}{ }^{\bullet-}$ in the gas-phase $[5,11]$.

\section{Acknowledgement}

This study has been with funding from the European Research Council under the European Union's Seventh Framework Programme (FP/2007-2013) / ERC Grant Agreement 290852 AIRSEA.

\section{References.}

1. R. C. Averett, J. A. Leenheer, D. M. McKnight, K.A. Thorn (Eds), Humic substances in the Swannee River, Georgia: Interactions, Properties and proposed structures, Open-file report 87-557, US Geological Survey, Denver, CO, 1989

2. C. S. Foote, in: W. A. Pryor (ed), Free radicals in biology, Academic Press Inc, New York, 1976, Vol. II 
3. S. Canonica, U. Jans, K. Stemmler, J. Hoigné, Environ. Sci. Technol. 29 (1995) 1822

4. S. Canonica, B. Hellrung, J. Wirz, J. Phys. Chem. A 104 (2000) 1226

5. A. Jammoul, S. Dumas, B. D’Anna, C. George, Atmos. Chem. Phys. 9 (2009) 4229

6. D. Vione, V. Maurino, C. Minero, E. Pelizzetti, M.A.J. Harrison, R.-J. Olariu, C. Arsene, Chem. Soc. Rev. 35 (2006) 441

7. B. Nozière, P. Dziedzic, A. Cordóva, J. Phys. Chem. A 112 (2009) 231

8. G. Yu, A. R. Bayer, M. M. Galloway, K. J. Korshavn, C. G. Fry, F. N. Keutsch, Environ. Sci. Technol. 45 (2011) 6336

9. M. M. Galloway, P. S. Chhabra, A. W. H. Chan, J. D. Surratt, R. C. Flagan, J. H. Seinfield, F. N. Keutsch, Atmos. Chem. Phys. 9 (2009) 3331

10. R. Volkamer, P. J. Ziemann, M. J. Molina, Atmos. Chem. Phys. 9 (2009) 1907

11. K. Z. Aregahegn, B. Nozière, C. George, Faraday Discuss. (2013) DOI: 10.1039/C3FD00044

12. C. J. Kampf, R. Jakob, T. Hoffmann, Atmos. Chem. Phys. 12 (2012) 6323

13. M. Trainic, A.A. Riziq, A. Lavi, Y. Rudich, J. Phys. Chem. A 116 (2012) 5948

14. L. W. Lion, J. O. Leckie, Ann. Rev. Earth Planet. Sci. 9 (1981) 449

15. B. Forte, B. Malgesini, C. Piutti, F. Quartieri, A. Scolaro, G. Papeo, Mar. Drugs 7 (2009) 705

16. R. Sinreich, S. Coburn, B. Dix, R. Volkamer, Atmos. Chem. Phys. 10 (2010) 11359

17. M. C. Facchini, S. Decesari, M. Rinaldi, C. Carbone, E. Finessi, M. Mircea, S. Fuzzi, F. Moretti, E. Tagliavini, D. Ceburnis, C. D. O’Dowd, Environ. Sci. Technol. 42 (2008) 9116

18. P. S. Liss, R. A. Duce, The Sea Surface and Global Change, Cambridge University Press, Cambridge, UK, 1997 
19. D. Clifford,D. J. Donaldson, M. Brigante, B. D’Anna, C. George, Environ. Sci. Technol. 42 (2008) 1138

20. D. I. Reeser, A. Jammoul, D. Clifford, M. Brigante, B. D’Anna, C. George, D. Donaldson, J. Phys. Chem. C 113 (2009) 2071

21. M. Martino, B. Leze, A. R. Baker, P. S. Liss, Geophys. Res. Lett. 39 (2012) L05809

22. D. I. Reeser, C. George, D. J. Donaldson, J. Phys. Chem A 113 (2009) 8591

23. C. D. O’Dowd \& G. de Leeuw, Phil. Trans. R. Soc. A 365 (2007) 1753

24. L. J. Carpenter, Chem. Rev., 103 (2003) 4953

25. J. L. Jimenez, J. T. Jayne, Q. Shi, C. E. Kolb, D. R. Worsnop, I. Yourshaw, J. H. Seinfield, R. C. Flagan, X. Zhang, K. A.Smith, J. W. Morris, P. Davidovits, J. Geophys. Res. 5 (2003) 108

26. G. McFiggans, H. Coe, R. Burgess, J. Allen, M. Cubison, M.R. Alfarra, R. Saunders, A. Saiz-Lopez, J. M. C. Plane, D. J. Wevill, L. J. Carpenter, A. R. Rickard, P. S. Monks, Atmos. Chem. Phys. 4 (2004) 701

27. A. Saiz-Lopez, J. M. C. Plane, A. R. Baker, L. J. Carpenter, R. von Glasow, J. C. Gomez Martin, G. McFiggans, R. W. Saunders, Chem. Rev. 112 (2012)

28. J. P. D. Abbatt, J. L. Thomas, K. Abrahamsson, C. Boxe, A. Granfors, A. E. Jones, M. D. King, A. Saiz-Lopez, P. B. Shepson, J. Sodeau, D. W. Toohey, C. Toubin, R. von Gasow, S. N. Wren, X. Yang, Atmos. Chem. Phys. 12 (2012) 6237

29. K. W. Oum, M. J. Lakin, D. O. DeHaan, T. Brauers, B. J. Finlayson-Pitts, Science 279 (1998) 74

30. J. M. Lázaro Martínez, P. N. Romasanta, A. K. Chattah, G. Y. Buldain, J. Org. Chem. 75 (2010) 3208

31. A. M. Braun, M.-T. Maurette, E. Oliveros (Eds.), Technologie Photochimique, Presses Polytechniques Romandes, Lausanne, Suisse, 1986 
32. C. Chahidi, M. Aubailly, A. Momzikoff, M. Bazin, R. Santus, Photochem. Photobiol. $33(1981) 641$

33. M. J. Kennish (ed), Practical handbook of marine science, CRC Press LLC, Florida, USA, 2001

34. W. Chang, B. G. Heikes, M. Lee, Atmos. Environ. 38 (2004) 1053

35. J. K. Hurley, H. Linschitz, A. Treinin, J. Phys. Chem. 92 (1988) 5151

36. S. L. Murov, I. Carmichael, G. L. Hug, Handbook of Photochemistry $2^{\text {nd }}$ edition, Marcel Decker Inc., 1993

37. R. Devonshire, J. J. Weiss, J. Phys.Chem. 72 (1968) 3815

38. G. L. Hug, Optical spectra of nonmetallic inorganic transient species in aqueous solutions, NSRDS-NBS, Washington, 1981

39. B.G. Ershov, E. Janata, Phys. Chem. Lett. 372 (2003) 195

40. Q. G. Mulazzani, G. V. Buxton, Chem. Phys. Lett. 421 (2006) 261

41. G. V. Buxton, M. Bydder, G. A. Salomon, J. E. Williams, Phys. Chem. Chem. Phys. 2 (2000) 237

42. H. Büchler, R. E. Bühler, Chem. Phys. 16 (1976) 9

43. I. Lampre, J.-L. Marignier, M. Mirdamadi-Esfahani, P. Pernot, P. Achirel, M.

Mostafavi, J. Phys. Chem. A 117 (2013) 877

44. M. Mirdamadi-Esfahani, I. Lampre, J.-L. Marignier, V. de Waele, M. Mostafavi, Rad. Phys. Chem. 78 (2009) 106

45. B. G. Ershov, Russ. Chem. Rev. 73 (2004) 101

\section{Figures:}




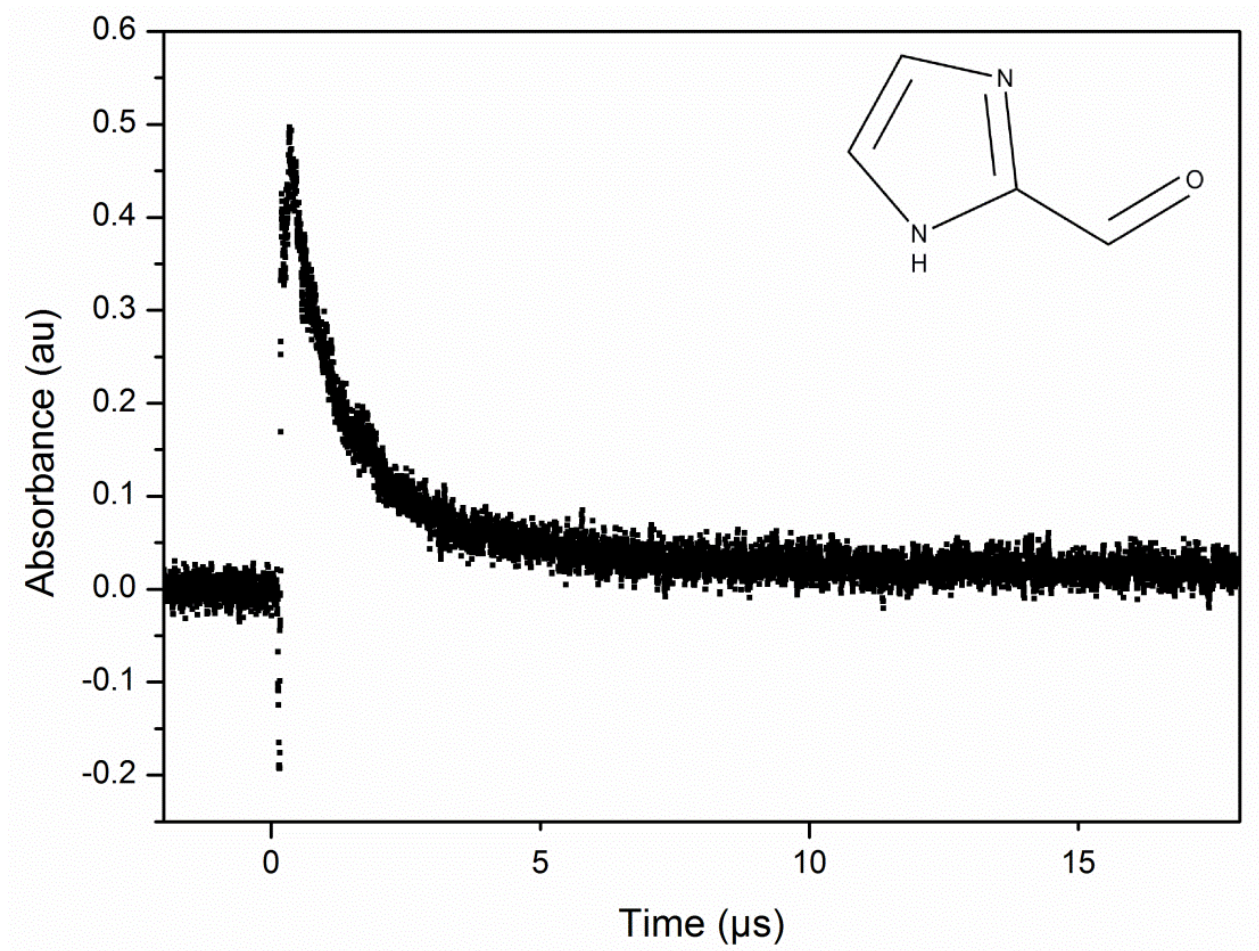

Figure 1: Transient absorption decay obtained at $330 \mathrm{~nm}$ of the IC triplet state in a deoxygenated aqueous solution of 0.25 mM IC alone (-)

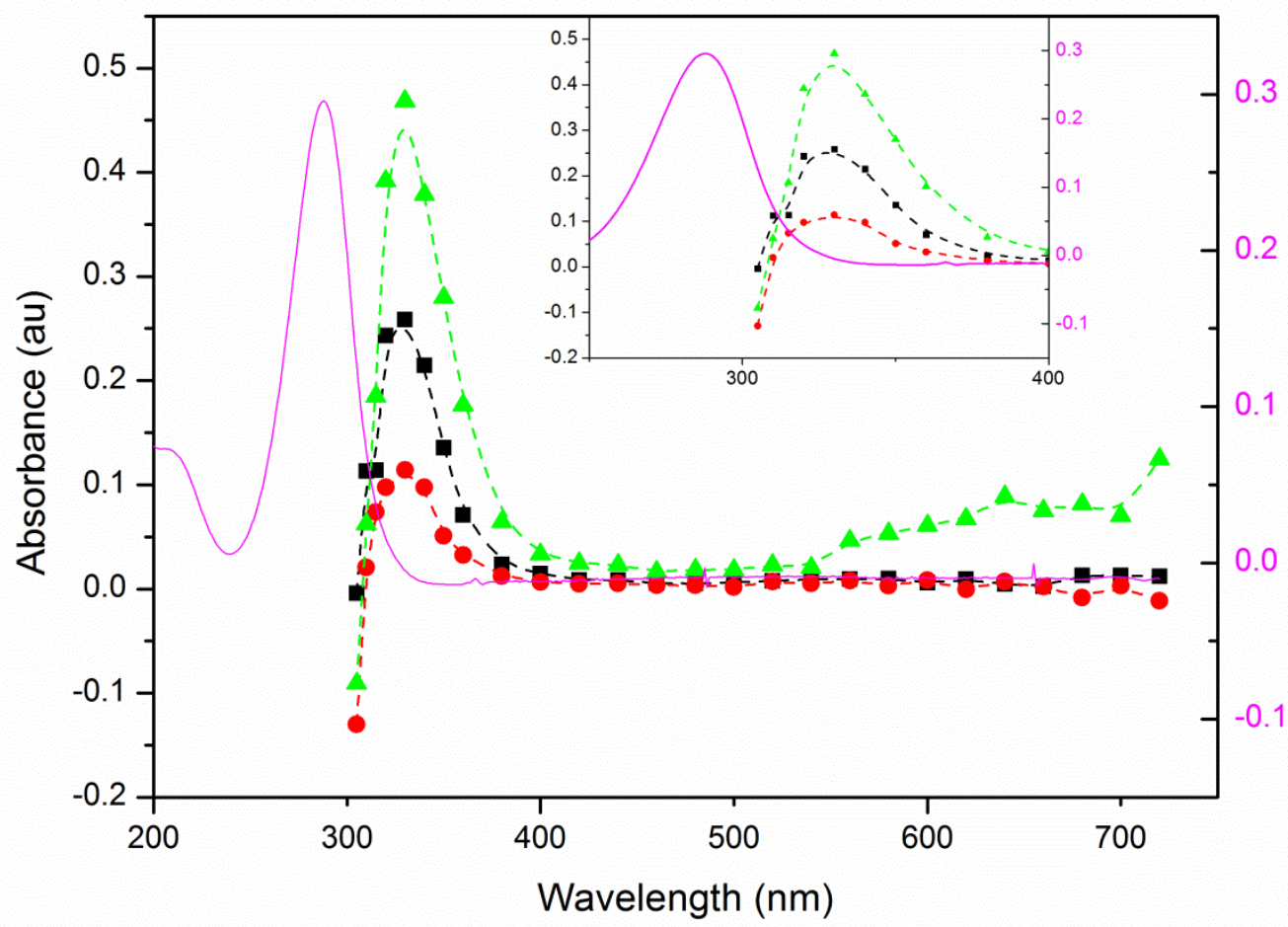

Figure 2: Absorption spectrum of aqueous solution of IC (0.25mM) recorded $330 \mathrm{~ns}(\mathbf{m}), 1 \mu \mathrm{s}$ $(\bullet)$ and $2 \mu \mathrm{s}(\triangle)$ after the laser pulse. The solid line (-) shows the absorption spectrum of a solution of 0.5mM IC (right Y scale) 


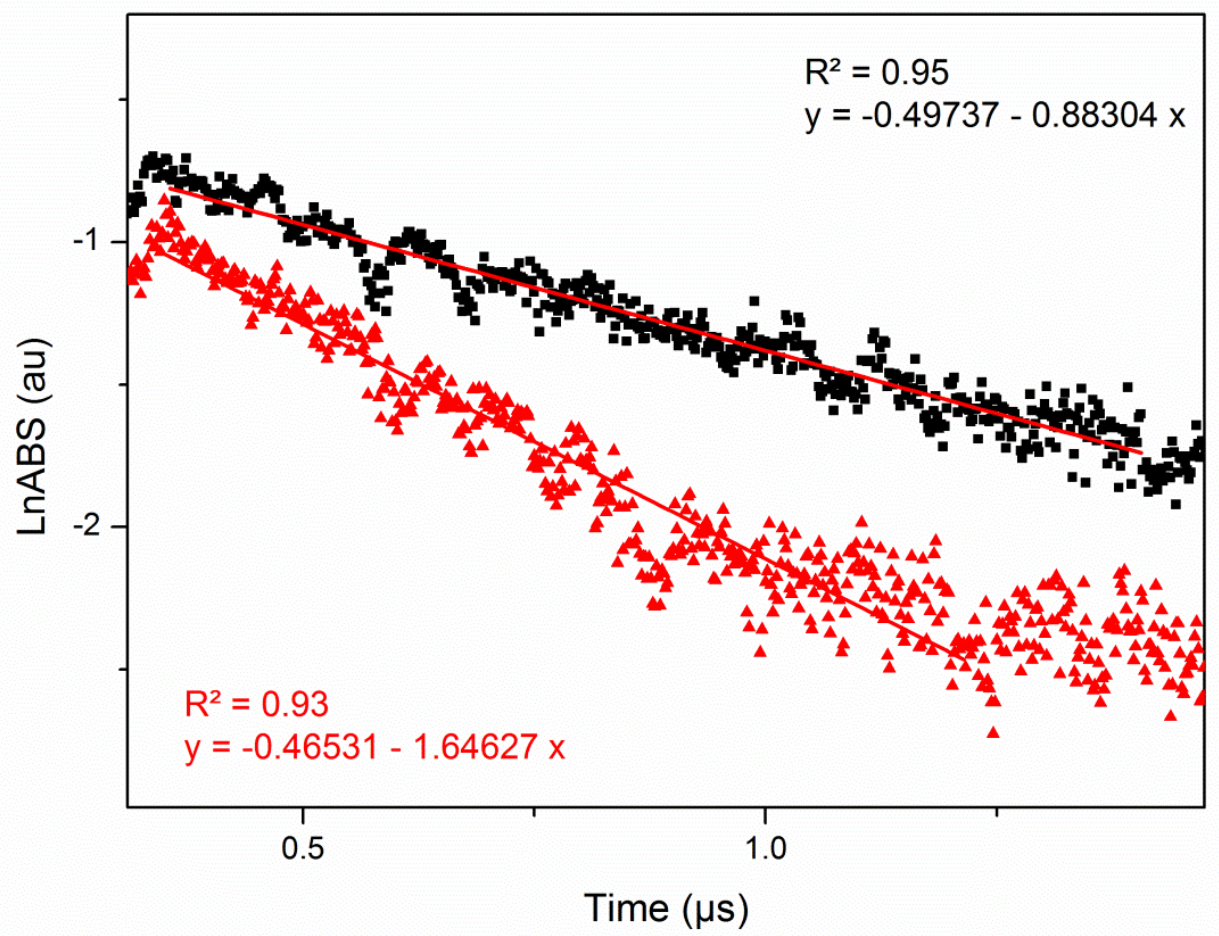

Figure 3: Log plot of a transient absorption decay obtained at $330 \mathrm{~nm}$ of the IC triplet state in a deoxygenated aqueous solution of $0.25 \mathrm{mM} \mathrm{IC}$ alone (-) and in presence of $0.25 \mathrm{mM} \mathrm{NaI}$ ( $\Delta$ ) and the linear fits showing a greater slope and thus faster decay in presence of NaI

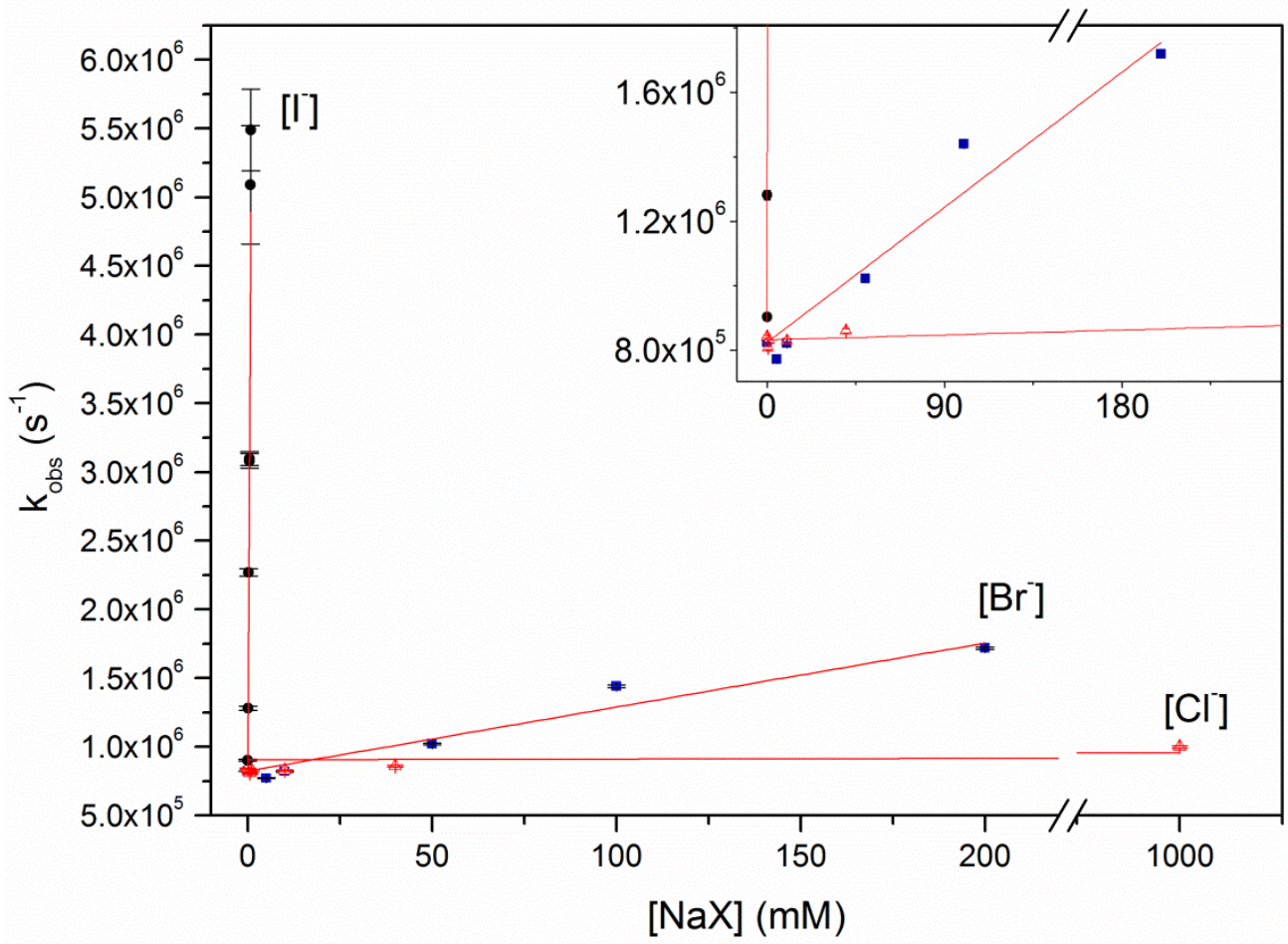

Figure 4: Stern-Volmer plot of the pseudo-first order rate coefficients $k_{\text {obs }}$ of IC triplet state quenching in function of the halide concentrations. 


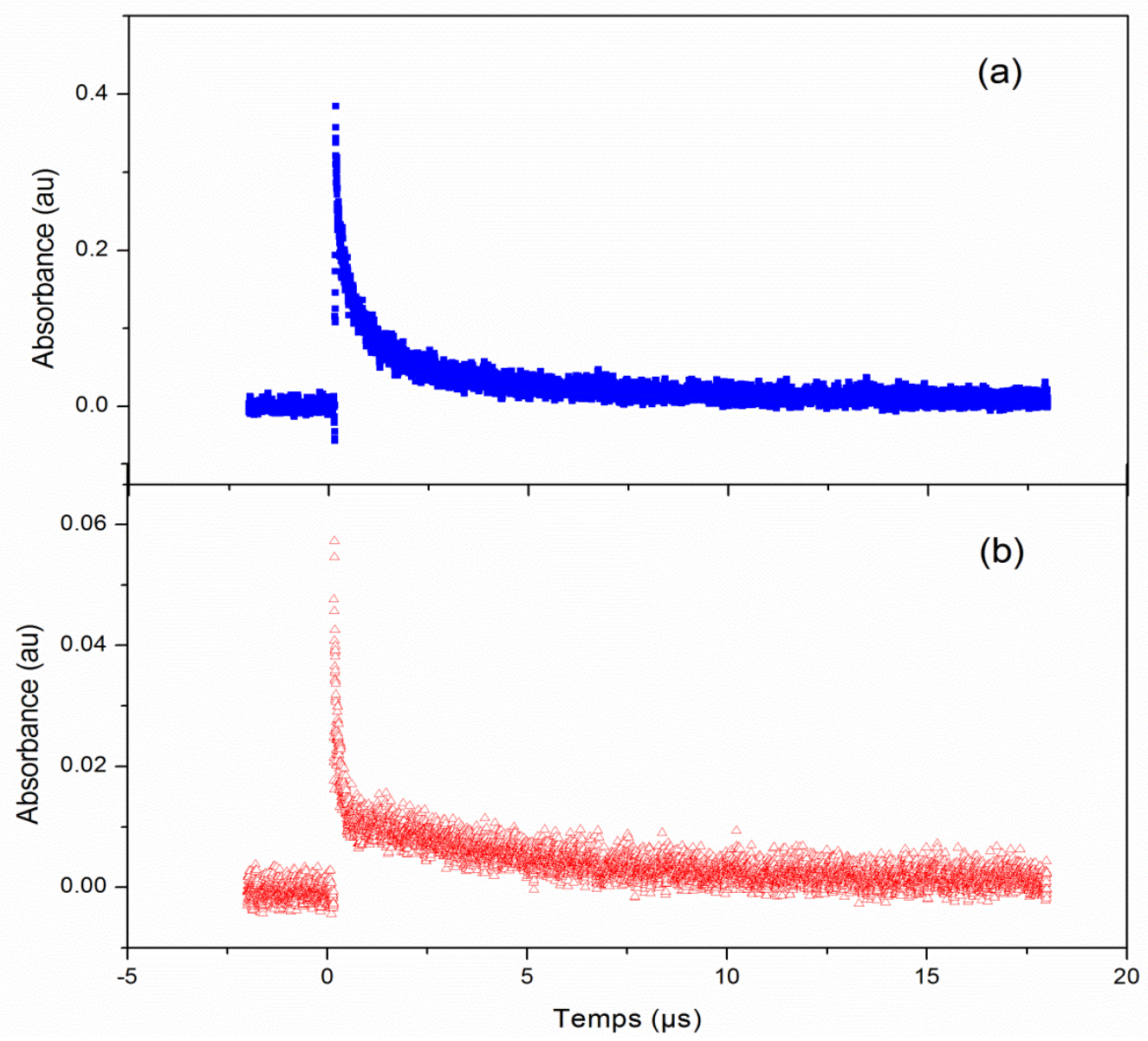

Figure 5: Transient absorption decay of ${ }^{3} \mathrm{IC}^{*}$ (a) in presence of $300 \mathrm{mM} \mathrm{NaBr}(\mathbf{\square})$ monitored at $355 \mathrm{~nm}$ and (b) in presence of $0.4 \mathrm{mM} \mathrm{NaI}(\Delta)$ monitored at $380 \mathrm{~nm}$, showing a biexponential decay.

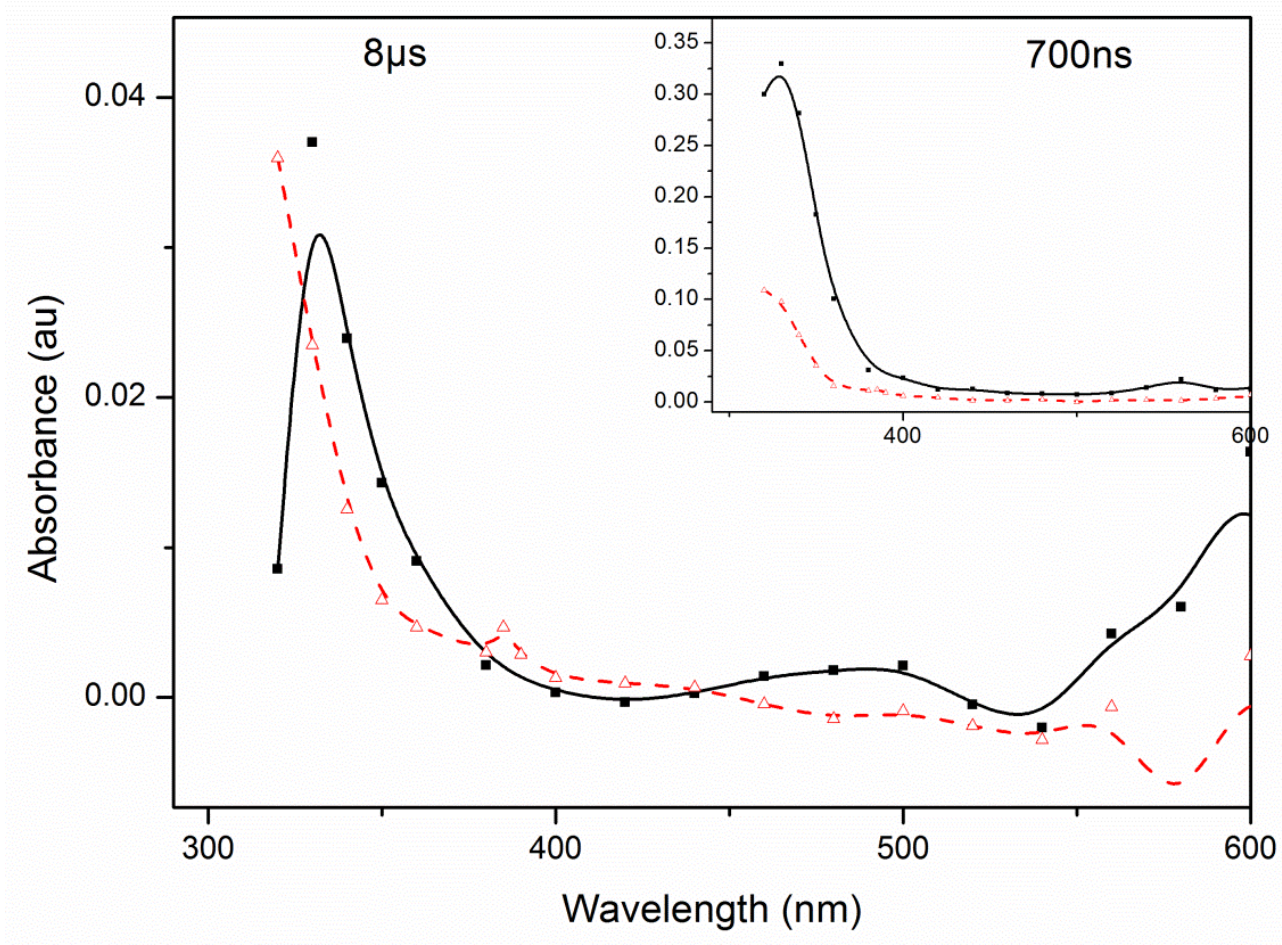


Figure 6: Absorption spectrum of IC $(0.25 \mathrm{mM})$ in presence of $\mathrm{NaI}(0.4 \mathrm{mM})$ registered at 8 $\mu$ s after the laser pulse, showed as --- $\Delta$, featuring a peak around $385 \mathrm{~nm}$, not observed in the absorption spectrum of IC alone (-). At shorter times after the laser pulse (700 ns, insert), the spectrum of IC in presence of $\mathrm{NaI}(---\Delta)$ is less intense at all wavelengths than the spectrum of IC only (-).

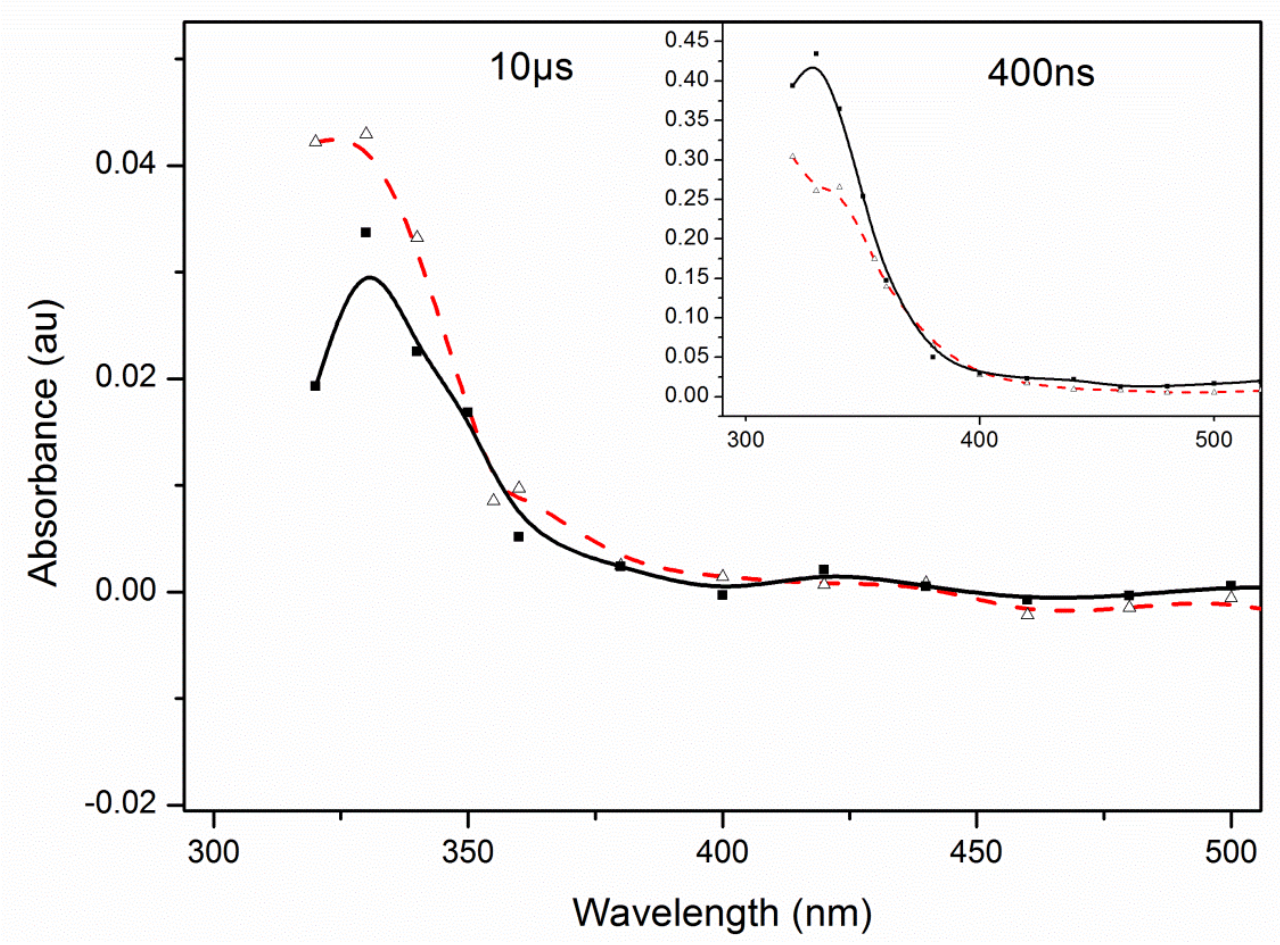

Figure 7: Absorption spectrum of IC $(0.25 \mathrm{mM})$ in presence of $\mathrm{NaBr}(300 \mathrm{mM})$ showing higher absorption around $360 \mathrm{~nm}(---\Delta)$ than the absorption spectrum of IC alone (-), registered at $10 \mu \mathrm{s}$ after the laser impuls. At shorter times after the laser impuls (400 ns, insert), the spectrum of IC in presence of $\mathrm{NaBr}(---\Delta)$ is less intense at all wavelengths than the spectrum of IC only (- $\longrightarrow$ ). 